\title{
FAST MICRO AND
}

\section{SLOW MACRO}

\section{CAN AGGREGATION \\ EXPLAIN THE \\ PERSISTENCE OF \\ INFLATION?}

by Filippo Altissimo,

Benoît Mojon

and Paolo Zaffaroni 


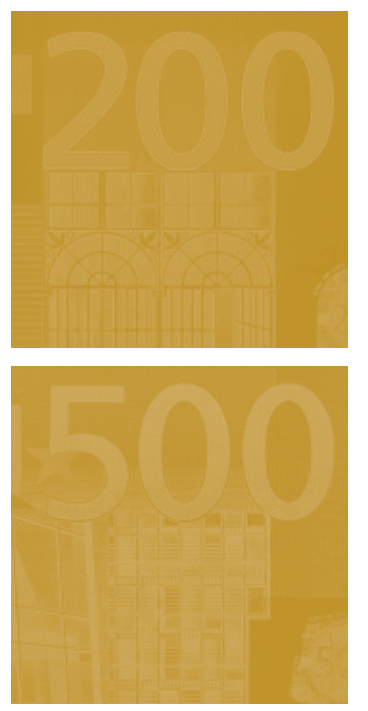

\section{WORKING PAPER SERIES}

NO 729 / FEBRUARY 2007

EUROSYSTEM INFLATION PERSISTENCE NETWORK

FAST MICRO AND SLOW MACRO

\section{CAN AGGREGATION EXPLAIN THE PERSISTENCE OF INFLATION? '}

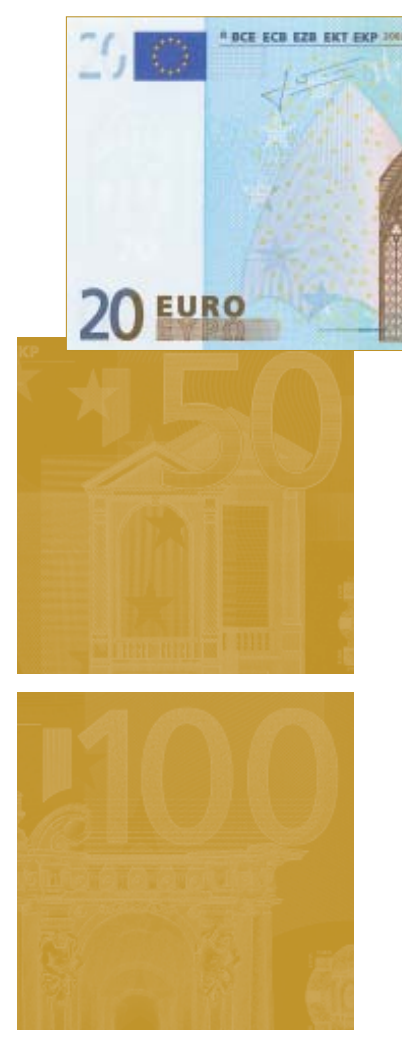

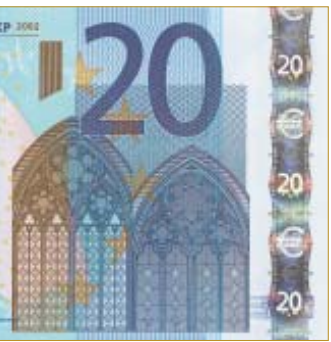

In 2007 all ECB publications feature a motif $€ 20$ banknote. by Filippo Altissimo ?, Benoît Mojon ${ }^{3}$ and Paolo Zaffaroni ${ }^{4}$

This paper can be downloaded without charge from http://www.ecb.int or from the Social Science Research Network electronic library at http://ssrn.com/abstract_id $=962034$.

I We are grateful to Laurent Baudry, Laurent Bilke, Hervé Le Bihan and Sylvie Tarrieu (Banque de France), Johannes Hoffmann (Deutsche Bundesbank) and Roberto Sabbatini and Giovanni Veronese (Banca d'ltalia) for sharing their data with us. We also would like to thank Anna-Maria Agresti and Martin Eiglsperger (ECB) for their assistance in the re-construction of historical time series of the German CPI sub-indices. Finally, we thank Gonzalo Camba-Méndez, Steven Cecchetti, M. Hashem Pesaran, Jim Stock and participants to the Eurosystem Inflation Persistence Network for helpful comments on previous presentations of this research. The opinions expressed here are those of the authors and do not necessarily reflect views of the European Central Bank or of the Federal Reserve Bank of Chicago. Any remaining errors are of course the sole responsibility of the authors. 2 European Central Bank, Kaiserstrasse 29, D-603 II Frankfurt am Main, Germany and Brevan Howard, Almack House, 28 King Street, London, SWIY 6XA, UK; e-mail: fliippo.altissimo@brevanhoward.com 3 European Central Bank, Kaiserstrasse 29, D-603 II Frankfurt am Main, Germany and Federal Reserve Bank of Chicago, 230 S La Salle St., Chicago, IL 60604, USA; e-mail:bmojon@frbchi.org 


\section{The Eurosystem Inflation Persistence Network}

This paper reflects research conducted within the Inflation Persistence Network (IPN), a team of Eurosystem economists undertaking joint research on inflation persistence in the euro area and in its member countries. The research of the IPN combines theoretical and empirical analyses using three data sources: individual consumer and producer prices; surveys on firms' price-setting practices; aggregated sectoral, national and area-wide price indices. Patterns, causes and policy implications of inflation persistence are addressed.

Since June 2005 the IPN is chaired by Frank Smets; Stephen Cecchetti (Brandeis University), Jordi Galí (CREI, Universitat Pompeu Fabra) and Andrew Levin (Board of Governors of the Federal Reserve System) act as external consultants and Gonzalo Camba-Mendez as Secretary.

The refereeing process is co-ordinated by a team composed of Günter Coenen (Chairman), Stephen Cecchetti, Silvia Fabiani, Jordi Galí, Andrew Levin, and Gonzalo Camba-Mendez. The paper is released in order to make the results of IPN research generally available, in preliminary form, to encourage comments and suggestions prior to final publication. The views expressed in the paper are the author's own and do not necessarily reflect those of the Eurosystem.

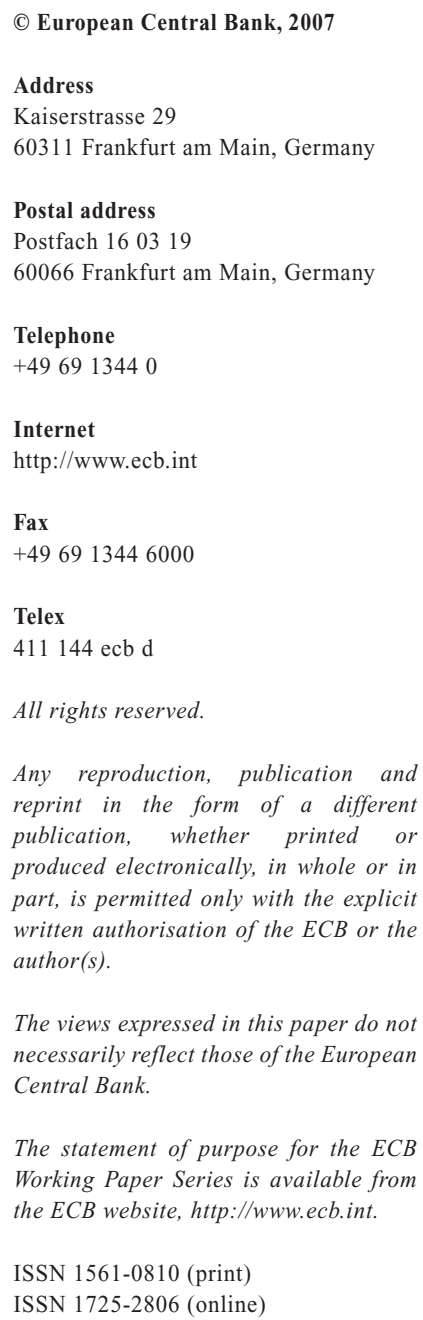

The views expressed in this paper do not necessarily reflect those of the European Central Bank. 


\section{CONTENTS}

Abstract 4

Non-technical summary 5

1 Introduction 6

2 Aggregation of heterogeneous AR(1) models 7

3 The Data 10

3.1 Choice of data and sample period 10

3.2 Definitions used in this study II

3.3 Behind the aggregation mechanism: common shock and heterogeneous parameters

4 Model: specification and estimation 15

4.1 The model I5

4.2 The estimation strategy 16

4.3 Results 17

4.3.1 Results for sectorial inflation rates $\quad 17$

4.3.2 Results for aggregate inflation rate 20

5 Conclusion 27

Data appendix 29

References 32

European Central Bank Working Paper Series $\quad 35$ 


\begin{abstract}
An aggregation exercise is proposed that aims at investigating whether the fast average adjustment of the disaggregate inflation series of the euro area CPI translates into the slow adjustment of euro area aggregate inflation. We first estimate a dynamic factor model for 404 inflation sub-indices of the euro area CPI. This allows to decompose the dynamics of inflation sub-indices in two parts: one due to a common "macroeconomic" shock and one due to sector specific "idiosyncratic" shocks. Although "idiosyncratic" shocks dominate the variance of sectoral prices, one common factor, which accounts for 30 per cent of the overall variance of the 404 disaggregate inflation series, is the main driver of aggregate dynamics. In addition, the heterogenous propagation of this common shock across sectoral inflation rates, and in particular its slow propagation to inflation rates of services, generates the persistence of aggregate inflation. We conclude that the aggregation process explains a fair amount of aggregate inflation persistence.
\end{abstract}

Keywords: Inflation dynamics, aggregation and persistence, euro area JEL classification: E31, E32 


\section{Non technical summary}

Understanding the source and degree of inflation persistence is key both to improve our ability to forecast inflation and to discriminate among different structural models of the economy. We want to know whether shocks to inflation are likely to have a persistent effects and what sort of business cycle adjustments govern the dynamics of inflation and real output. On the latter aspect, macroeconomists disagree on the importance of price stickiness (the fact that prices are not adjusted every period) for the business cycle. If prices are sticky, i.e. do not adjust to a change in the economic situation, then real output need to adjust. However, if prices can adjust to, say, the gap between demand and supply, then this gap should be negligible. Recently, research looked into micro level prices in order to solve this controversy. Because micro prices tend to adjust relatively frequently (one a quarter on average in the US and 3 times a year in the euro area), some have concluded that price stickiness cannot explain the persistence of inflation.

However, the theory of cross-sectional aggregation of dynamic processes show that slow macroeconomic adjustments may very well be consistent with much faster average speed of adjustments at the micro level. This paper uses sectoral prices of the euro area to test whether these explicit models of the aggregation process can solve the apparent dilemma between the flexibility of sectoral prices and the persistence of macroeconomic inflation.

We estimate a linear dynamic factor model for 404 sub-indices of the euro area CPI between 1985 and 2003. In the model, each inflation series depends on a macroeconomic shock, the common factor, and a subcategory (or "sectoral" thereafter) specific idiosyncratic factor.

We then aggregate back the 404 models of micro level inflation and decompose the dynamics of this aggregate into the effects of the common and the idiosyncratic shocks.

Our main findings can be summarized as follows. First, we find that one common factor accounts for 30 per cent of the overall variance of the 404 series. This share is twice as large if one focuses on low frequencies, i.e., on the persistent components of the series. Second, the propagation mechanism of shocks is highly heterogeneous across sectors. This heterogeneity is the prerequisite ingredient for the aggregation mechanism to be maximally effective. Third, the implied persistence from the aggregation exercise mimics remarkably well the persistence observed in the aggregate inflation. In particular, the cross-sectional distribution of the micro parameters implies an autocorrelation function of the aggregate CPI inflation which decays hyperbolically toward zero and displays long memory. Altogether, the high volatility and low persistence, observed on average at the level of sectoral inflation, is consistent with the aggregate smoothness and high persistence. 


\section{Introduction}

Understanding the source and degree of inflation persistence is key both to improve our ability to forecast inflation and to discriminate among different structural models of the economy. Successful out-of-sample forecasting of inflation requires in first instance to decide the appropriate degree of persistence and, eventually, of non-stationarity of the data generating process. The long adjustment of the aggregate inflation appears to be well approximated by a long memory stationary process, whose autocorrelation function decays very slowly ("hyperbolically") toward zero as the lag increases. Such a slow rate of decay has, in the case of inflation, led many empirical studies to assume a unit root behavior for aggregate inflation ${ }^{1}$.

Turning to models of the business cycle, price stickiness is seen by many as the key ingredient that allows micro founded DSGE models to deliver the inflation and output persistence that we see in macroeconomic data (see Sbordone, 2003, Galì and Gertler, 1999, Christiano et al., 2005, Smets and Wouters, 2003, among others.). Critics of sticky price models have stressed that the degree of price stickiness usually assumed are far too large to make economic sense (Chari, Kehoe and Mac Grattan, 2000) ${ }^{2}$ and inconsistent with the much faster average frequency of adjustments that can be observed in the micro data (Bils and Klenow, 2004 and Dhyne et al., 2005, Horváth and Coricelli, 2006).

However, the theory of cross-sectional aggregation of dynamic processes (see Robinson, 1978, Granger, 1980, Forni and Lippi, 1997, and Zaffaroni, 2004) show that slow macroeconomic adjustments may very well be consistent with much faster average speed of adjustments at the micro level. This paper uses sectoral prices of the euro area to test whether these explicit models of the aggregation process can solve the apparent dilemma between the flexibility of sectoral prices and the persistence of macroeconomic inflation.

To start with, aggregation is a necessary step in the construction of macroeconomic price indices from survey prices on individual goods and services. For instance, in the US the Bureau of Labor Statistics collects prices for approximately 80,000 goods and services each month, which are divided into 350 categories called entry level items; those data are aggregated up to the overall CPI. The link between the monthly micro price quotes for each entry level item, whose relative frequencies of changes has been analyzed by Bils and Klenow (2004) and Dhyne et al. (2005), and the aggregate CPI implies at least two layers of aggregation: the first one goes from the individual price records to the price index of the relevant subcategory. The second one relates the subcategories to the aggregate CPI. This paper focuses on this second layer.

We estimate a linear dynamic factor model for 404 sub-indices of the euro area CPI between 1985 and 2003. In the model, each inflation series depends on a macroeconomic shock, the common factor, and a subcategory (or "sectoral" thereafter) specific idiosyncratic factor. We then aggregate back the 404 models of micro level inflation and decompose the dynamics of this aggregate into the effects of the common and the idiosyncratic shocks.

\footnotetext{
${ }^{1}$ See for instance O'Reilly and Whelan (2005) and references therein.

${ }^{2}$ See also Golosov and Lucas (2006) and Mackowiak and Wiederhot (2005).
} 
Our main findings can be summarized as follows. First, we find that one common factor accounts for 30 per cent of the overall variance of the 404 series. This share is twice as large if one focuses on low frequencies, i.e. on the persistent components of the series. Second, the propagation mechanism of shocks is highly heterogenous across sectors. This heterogeneity is the prerequisite ingredient for the aggregation mechanism to be maximally effective. Third, the implied persistence from the aggregation exercise mimics remarkably well the persistence observed in the aggregate inflation. In particular, the cross-sectional distribution of the micro parameters implies an autocorrelation function of the aggregate CPI inflation which decays hyperbolically toward zero and displays long memory. Altogether, the high volatility and low persistence, observed on average at the level of sectoral inflation, is consistent with the aggregate smoothness and high persistence.

This work is related to a recent stream of literature that stresses the importance of understanding micro heterogeneity and the aggregation process in order to explain the dynamic properties of aggregate variables. Imbs, Mumtaz, Ravn and Rey (2005) show that the persistence of aggregate real exchange rates is substantially magnified because the dynamics of disaggregated relative prices is heterogenous. Carvalho (2006) derives a generalized new Keynesian Phillips curve that accounts for heterogeneity in price stickiness across sectors and shows that the process of adjustment to nominal shocks tends to be more sluggish than in comparable identical firms economies. Altissimo and Zaffaroni (2004) show that the properties of aggregate income for the US can be reconciled with the dynamic properties of a cross section of individual level income extracted from the PSID panel. ${ }^{3}$

The paper is organized as follows. The following section presents the elements of cross-section aggregation relevant to our analysis. Section 3 presents the data used in the empirical analysis and addresses the presence of common factors across the price sub-indices. Section 4 introduces the micro model and the estimation methodology. It then discusses the estimation results and their implications for the aggregate persistence. Section 7 concludes.

\section{Aggregation of heterogeneous AR(1) models}

In this section we revisit, by means of examples, the relevant results on contemporaneous aggregation of heterogeneous ARMA models, when the number of units gets arbitrarily large (see

\footnotetext{
${ }^{3}$ On a related issue, Caballero and Engel (2005) have shown that if the adjustment process is lumpy or step-wise then estimating the speed of adjustment by linear method tend to over-estimate the speed of adjustment and that this effect washes out in the case of cross sectional aggregation but at a very low speed. Their result can be regarded as a criticism to the common practice of using linear method to measure persistence.

Clark (2003) and Boivin et al.(2006) also stress the importance of the decomposition of sectoral price dynamics into common aggregate shocks and sectoral idiosyncratic ones. They however do not model the aggregation process and its impact on inflation persistence.
} 
Robinson, 1978, Granger, 1980, and Zaffaroni, 2004). For sake of simplicity, let the $i$ th sub-index be described by an $A R(1)$ model

$$
y_{i t}=\alpha_{i} y_{i t-1}+\eta_{i t}
$$

where both the coefficients and the random shocks vary across units. When considering an arbitrarily large number of units, a convenient way to impose heterogeneity is to assume that the coefficients $\alpha_{i}$ are i.i.d. random drawn from some underlying distribution with probability density function $f(\alpha)$. Stationarity of each of the $y_{i t}$ then requires $\left|\alpha_{i}\right|<1$ a.s. or, alternatively, that $f(\alpha)$ has support $(-1,1)$. The random shock is the sum of a common and of an idiosyncratic component

$$
\eta_{i t}=u_{t}+\epsilon_{i t},
$$

with the $u_{t}$ being an $i . i . d$. sequence $\left(0, \sigma_{u}^{2}\right)$ and $\epsilon_{i t}$ being an $i . i . d$. sequence $\left(0, \sigma_{\epsilon, i}^{2}\right)$. The $\epsilon_{i, t}$ are also assumed independent across $i$ th. The aggregate variable is simply the sample average of the individual units.

It is well known that summing a finite number of ARMA processes yields again an ARMA process. For example, the sum of $n$ distinct $\operatorname{AR}(1)$ models, with different auto-regressive parameters, yields an $\operatorname{ARMA}(n, n-1)$. However, when $n$ goes to infinity, it turns out that under mild conditions on $f(\alpha)$, the limit of the aggregate as $n \rightarrow \infty$ will not belong to the class of ARMA processes, in contrast to the individual $y_{i t}$. We explore such a case.

In view of (2), by stationarity and linearity of the individual models it follows that

$$
Y_{n, t}=\frac{1}{n} \sum_{i=1}^{n} \frac{u_{t}}{1-\alpha_{i} L}+\frac{1}{n} \sum_{i=1}^{n} \frac{\epsilon_{i t}}{1-\alpha_{i} L}=U_{n, t}+E_{n, t},
$$

meaning that the aggregate could be decomposed into a common and idiosyncratic component. Although the statistical properties of each unit are well-defined, conditioning on $\alpha_{i}$, knowledge of the entire history of each individual $y_{i t}$, or at most for a finite number $n$ of them, is uninformative with respect to the distribution, $f(\alpha)$. However, when looking at an arbitrarily large number of units, the distribution $f(\alpha)$ will then entirely determine the properties of the limit aggregate, which we define as the limit (in mean-square) of the $Y_{n, t}$ for $n \rightarrow \infty$.

To this end, let us focus on the common component. This can be written as

$$
U_{n, t}=u_{t}+\hat{\mu}_{1} u_{t-1}+\hat{\mu}_{2} u_{t-2}+\ldots+\ldots
$$

setting $\hat{\mu}_{k}=\frac{1}{n} \sum_{i=1}^{n} \alpha_{i}^{k}$ for every $k$. When $n$ gets large, by the strong law of large numbers, each $\hat{\mu}_{k}$ will converge a.s. to the population moments of the $\alpha_{i}$, i.e. $\mu_{k}=\int \alpha^{k} f(\alpha) d \alpha$. The dynamic pattern of the $\mu_{k}$ represents the impulse response of the common shocks $u_{t}$ on the aggregate.

The dynamic pattern of the $\mu_{k}$ uniquely depends on the shape of the density $f(\alpha)$ and in particular on its behavior around the unit root. In particular, Zaffaroni (2004) shows that for any distribution whose behavior around unit root can be represented, up to a scaling coefficient, as $(1-\alpha)^{q-1}, q>0$, then it follows $\mu_{k} \sim c k^{-q}$ as $k \rightarrow \infty$, where $\sim$ denotes asymptotic equivalence. 
Thus, an exponential rate of decay of the impulse response of the micro units $\left(\alpha_{i}^{k}\right)$ corresponds to an hyperbolic rate of decay for the aggregate $\left(k^{-q}\right)$, that depends on $f(\alpha)$ through $q$. The smaller is $q$, the denser is $f(\alpha)$ distribution around the unit root (i.e. more micro units are very persistent), the longer it takes for $\mu_{k}$ to converge towards zero (recall that $q>0$ for $f(\alpha)$ to be integrable and thus be a proper probability density function).

To further illustrate this result, let us consider the following parametrization of $f(\alpha)$

$$
f(\alpha)=\left\{\begin{array}{cc}
B^{-1}(p, q) \alpha^{p-1}(1-\alpha)^{q-1}, & 0 \leq \alpha<1 \\
0, & \text { otherwise }
\end{array}\right.
$$

corresponding to the $\operatorname{Beta}(p, q)$ distribution, with parameters $p, q>0$. Table 1 reports the dynamic pattern of $\mu_{k}$ for various values of $q$ with the mean of $\operatorname{Beta}(p, q)$ set equal to $0.8\left(\mu_{1}=0.8\right){ }^{4}$ The results are contrasted with the case of homogeneous $\mathrm{AR}(1)$, with impulse response given by $\mu_{1}^{k}$ (auto-regressive coefficient equal to $\mu_{1}$ ). This example illustrates the effect of aggregation taking, as a benchmark, the case where all sub-indices are similar AR(1) processes with autoregressive coefficient equal to $\mu_{1}=0.8$, i.e are quite persistent.

Table 1: Impulse response functions of limit aggregate $U_{t}$

\begin{tabular}{|c|c|c|c|c|c|c|}
\hline \multirow[t]{2}{*}{$k$} & \multicolumn{5}{|c|}{$f(\alpha)$} & \multirow[t]{2}{*}{$\mu_{1}^{k}$} \\
\hline & $q=$ & 0.2 & 0.7 & 1 & 3 & \\
\hline 1 & & 0.8 & 0.8 & 0.8 & 0.8 & 0.8 \\
\hline 2 & & 0.72 & 0.67 & 0.66 & 0.65 & 0.64 \\
\hline 5 & & 0.61 & 0.48 & 0.44 & 0.37 & 0.33 \\
\hline 10 & & 0.54 & 0.33 & 0.28 & 0.17 & 0.11 \\
\hline 50 & & 0.39 & 0.12 & 0.07 & 0.01 & $1.4 \times 10^{-5}$ \\
\hline 200 & & 0.36 & 0.09 & 0.05 & 0.01 & $4.1 \times 10^{-20}$ \\
\hline
\end{tabular}

The effects of heterogeneity and aggregation are substantial: the impulse response function of the aggregate process (common component) decays towards zero with a much slower decay than the homogeneous coefficient case. Note that the smaller $q$ is, the larger is the mass of the distribution around the unit root and the slower will the effect of random shocks fade away. In other words, the average impulse response is markedly different from the impulse response of the average.

The characterization of the impulse response implies a neat representation of the autocovariance function (acf) and spectral density of the limit aggregate $U_{t}$. In particular, when $q>1 / 2$, the autocovariance function of the limit aggregate process satisfies

$$
\operatorname{var}\left(U_{t}\right)<\infty, \operatorname{cov}\left(U_{t}, U_{t+k}\right) \sim c k^{1-2 q} \text { as } k \rightarrow \infty,
$$

with $c$ being an arbitrary scaling constant. One can easily see that $\operatorname{cov}\left(U_{t}, U_{t+k}\right)$ decays toward zero albeit at an hyperbolically rate. When $q>1$, the density $f(\alpha)$ will have little mass around

\footnotetext{
${ }^{4}$ In order to consider $\operatorname{Beta}(p, q)$ distributions with different $q$ but same mean $\mu=0.8$, one needs to set $p=$ $\left(\frac{\mu}{1-\mu}\right) q$.
} 
the unit root $(f(\alpha) \downarrow 0$ as $\alpha$ approaches 1$)$ and the $\operatorname{cov}\left(U_{t}, U_{t+k}\right)$ is summable, meaning that it decays to zero sufficiently fast. This is known as a case of short memory. Instead, when $1 / 2<q<1$, large mass of the $f(\alpha)$ will be around the unit root $(f(\alpha) \uparrow \infty$ for $\alpha$ approaching $1)$. For this case, the $\operatorname{cov}\left(U_{t}, U_{t+k}\right)$ still decays toward zero but too slowly to ensure summability, resembling the classical definition of long memory. In particular, we say that $U_{t}$ is a stationary process displaying long memory with memory parameter $0<d<1 / 2$ whenever

$$
\operatorname{cov}\left(U_{t}, U_{t+k}\right) \sim c k^{2 d-1}, \quad \text { as } k \rightarrow \infty .
$$

The previous Beta distribution example yields a particular case of (6) setting $d=1-q$. Hence, the smaller is $q$, the larger is the frequency of units whose $\alpha_{i}$ is close to unity, and the more persistent is the limit aggregate. Finally in the extreme case when $0<q<1 / 2$, the aggregate process will be non stationary; this is evident since the autocovariance function does not even decay to zero as $k$ increases.

Two final remarks are warranted. First, the idiosyncratic component can be neglected as long as the aggregate is stationary, because their effect should vanish through aggregation. However, in the case of non-stationary aggregate, namely $0<q<1 / 2$, the idiosyncratic components of the very persistent micro processes can still show up in the aggregate. Second, the above results can be extended within a general ARMA framework where the implication for aggregation depend on the shape of the distribution of the largest autoregressive root of the ARMA process. See Zaffaroni (2004) for more details.

\section{The data}

The data consist of 404 seasonally adjusted quarter over quarter (q-o-q) inflation rates of CPI sub-indices from France, Germany and Italy. In this section, we first discuss our choice of data and sample period. Second, we present descriptive statistics on sectoral and aggregate inflation and their persistence. Finally, we propose some evidence on the presence of a common driver among the 404 inflation subindices.

\subsection{Choice of data and sample period}

We use CPI data rather than HICP because the latter are available only since 1995. However, because earlier data are not readily available in all the countries of the euro area, we limited our data to France, Germany and Italy. These countries together account for roughly 70 per cent of the euro area population and consumption. The three CPI original databases together comprise 470 sub-indices. 66 of these were not suitable for estimation of an ARMA either because they have too few observations (e.g. some sub-indices are available only since 2000), or because they correspond to items which prices are set at discrete intervals (e.g. Tobacco or Postal services). 
We are left with 404 "well-behaved" series that are proper to be modeled. ${ }^{5}$

We focus on the post 1985 data for two reasons. First, the German data are not available beforehand. Second, many studies have showed that the mid-eighties marked a significant break in average inflation in most OECD countries. Corvoisier and Mojon (2005) suggests that Italian, French and German time series of inflation all admit a break in the mid-eighties. Bilke (2005) obtains that most of the 148 French sectoral inflation rates (exactly our data as far as France in concerned) admit a break in their mean around 1985 and very infrequently at any other time of the 1972-2003 sample period. Bilke argues that this coincidence of changes in the dynamics of sectoral inflation rates may actually reflect a major shift in French monetary policy regime in the mid-1980's. According to Gressani, Guiso and Visco (1988), such a regime shift is also very likely to happen at about the same time in Italy. As regards Germany, where the monetary policy regime was more stable, the breaks in average inflation of its two largest trade partners is a major event in itself.

For all these reasons, we deem the post-1985 sample as appropriate to study the persistence of inflation in the euro area. This choice of sample leaves us up to 77 observations of q-o-q inflation rates for each of the 404 sub-indices.

\subsection{Sectoral inflation series: descriptive statistics}

We now turn to the properties of the sub-sector inflation rates. Table 2 reports descriptive statistics of aggregate inflation and of the distribution of the 404 sectoral inflation rates. First, the inflation sectoral means are quite disperse with fifty per cent of their distribution ranging from 1.8 to 4.2 percent. The mean of aggregate inflation is 2.6 percent. Second, sectoral inflation is noticeably more volatile than aggregate inflation. On average, the standard deviation of the inflation sub-indices is equal to 3.5 percent, i.e. nearly three times as large the standard deviation of the aggregate. This much higher volatility is a common feature of the inflation rates of sectoral prices as shown in Bilke (2005) and Clark (2003). Third, the persistence of sectoral inflation rates is also clearly smaller than the one of the aggregate inflation series. The largest root of the ARMA fitted to the aggregate inflation amounts to $0.93 .{ }^{6}$ This roughly equals to the 75 th percentile of the sector's persistence.

If the sectoral data would already display long memory, so that (6) holds for the large majority of the sub-indices inflation rates, then the aggregation exercise would be trivial. The last column of the table, which reports the statistics relative to the distribution of estimated long memory parameters, based on the the parametric Whittle estimator (see Brockwell and Davis, 1991), confirms that only very few sectoral inflation rates exhibit fractional integration. $d$ is not different from or close to -0.5 for a vast majority of the cross-section. However, as shown below, our

\footnotetext{
${ }^{5}$ See the Appendix for the source of the data and the data treatment.

${ }^{6}$ The largest root is the one associated to the best $\operatorname{ARMA}(p, q)$ as selected by the Akaike (AIC) criteria with $0 \leq p, q \leq 4$, estimated on the q-o-q inflation time series for the 1985q2-2004q2 sample, using the ARMAX procedure of MatLab.
} 
estimate of $d$ for the aggregate inflation rate is 0.18 , well above the 75 th percentile of the sectoral $d$ parameters $(-0.18)$. Fourth, we observe sharper differences in persistence across the main sectoral groupings of the CPI (processed food, unprocessed food, energy, non-energy industrial goods-NEIG- and services) than across countries. The gap between the ARMA largest root of the inflation process of unprocessed food prices (0.52) and one of the energy (0.78) is wider than between the root associated to the ARMA processes fitted on the inflation of German, French and Italian prices. Comparing the main groupings of CPI sub-indices across countries, we also find that the sectoral hierarchy at the euro area level applies within each country.

To conclude, we find clear evidence that the inflation rates of the individual sub-indices are way more volatile and much less persistent than the inflation rate of the aggregate CPI index. Moreover, volatility and persistence are more sector than country dependent.

Table 2: Descriptive statistics of the 404 sectoral inflation rates

(first two columns annualized q-o-q inflation rates)

\begin{tabular}{ccccc}
\hline & Mean & Stand. dev. & Larg. ARMA root & Long mem. d \\
Aggregate of 404 & 2.6 & 1.1 & 0.93 & 0.18 \\
\hline \multicolumn{5}{c}{ Cross section characteristics } \\
\hline Weighted mean & 2.6 & 3.6 & 0.78 & -0.33 \\
Unweighted mean & 2.4 & 3.5 & 0.72 & -0.36 \\
Minimum & -11.3 & 0.7 & -0.81 & -0.50 \\
25th percentile & 1.8 & 1.7 & 0.71 & -0.50 \\
Median & 2.6 & 2.5 & 0.83 & -0.43 \\
75th percentile & 4.2 & 4.0 & 0.90 & -0.18 \\
Maximum & 8.1 & 25.4 & 1.02 & 0.32 \\
\hline France & 1.8 & 3.0 & 0.72 & -0.34 \\
Germany & 1.5 & 3.2 & 0.71 & -0.34 \\
Italy & 3.6 & 4.3 & 0.73 & -0.36 \\
Processed food & 2.6 & 3.1 & 0.68 & -0.20 \\
Unprocessed food & 2.3 & 3.9 & 0.52 & -0.33 \\
NE Indus. goods & 2.0 & 2.2 & 0.77 & -0.38 \\
Energy & 1.9 & 8.4 & 0.78 & -0.37 \\
Services & 3.3 & 3.0 & 0.74 & -0.33 \\
\hline
\end{tabular}

\subsection{Behind the aggregation mechanism: common shock and heterogeneous parameters}

This section assesses the two elements that play a crucial role in shaping the effect of crosssection aggregation of time series: the presence of common shocks and the heterogeneity in the propagation mechanism of those shocks. This means that, using the notation of Section 2, there 
is a common shock $u_{t}$ and that the $\alpha_{i}$ are different across $i$. We start by investigating the presence of common shocks in the cross-section of the inflation sub-indices before enquiring on the heterogeneity in the propagation of this common shock across sectors.

Following the recent literature on factor model in large cross-sections ${ }^{7}$ we estimate the first ten dynamic principal components of the autocovariance structure of the sectoral inflation series. The dynamic principal component analysis provides indications on the number of common shocks explaining the correlation structure in the data (see Forni et al., 2000).

Figure 1 presents the spectrum of the first ten dynamic principal components ${ }^{8}$ of the 404 inflation time series.

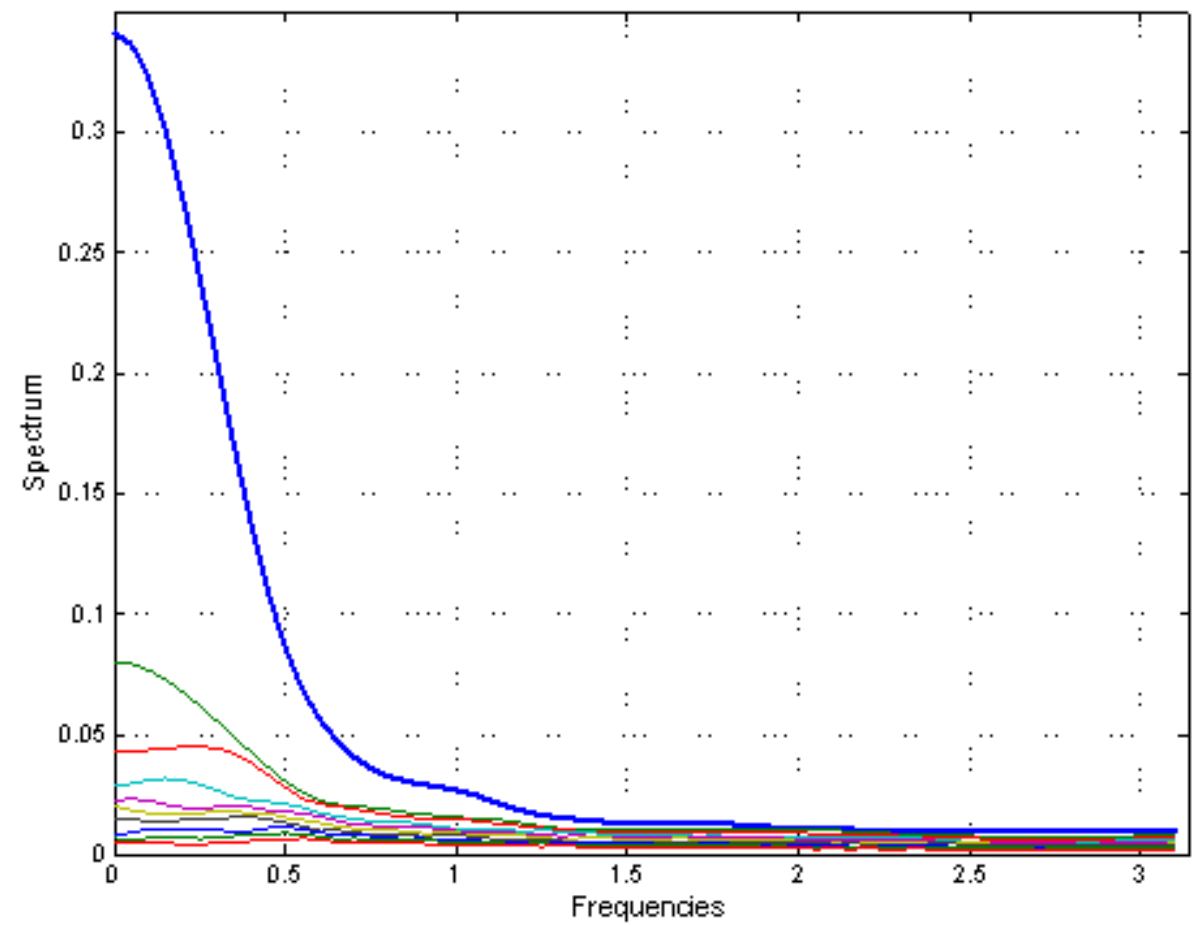

Figure 1: First ten principal components.

The variance of sectoral inflation is strikingly dominated by one common factor. Figure 1 also shows that this first common factor is the only one of which the spectrum is concentrated on

\footnotetext{
${ }^{7}$ See Forni et al. (2000), Stock and Watson (2002) and the application by Clark (2003) to US disaggregate consumption deflators.

${ }^{8}$ Dynamic principal components are calculated as the eigenvalue decomposition of the multivariate spectra of the data at each frequency (see Forni et al. (2000) for details). The autocovariance function up to eight lags has been used in the construction of the multivariate spectral matrix. The data has been standardized to have unit variance before estimating the multivariate spectra.
} 
low frequencies. Hence this factor is the driver of persistence observed in sectoral inflation. ${ }^{9}$ The other factors account for a much smaller share of the variance than the first one. They are also more equally relevant at all frequencies, as indicated by their relatively flat patterns in Figure $1 .^{10}$

On the basis of these results, we opt for a factor model of the sectoral inflation series that admits a single common shock. We then model the sectoral inflation time series as:

$$
y_{i t}=\delta_{0 i}+\Psi_{i}(L) u_{t}+\xi_{i t}, i=1, \ldots, N
$$

where $u_{t}$ is the common shock, $\xi_{i t}$ is a stationary idiosyncratic component, orthogonal to the common one and $\delta_{0 i}$ is the constant term. $\Psi_{i}(L)$ is a unit specific lag polynomial which represents the propagation of the common shock through the $y_{i t}$ process.

We now look at whether the propagation mechanism of the common shock in the crosssection of price sub-indices is homogenous across items. Still resorting to spectral analysis, we estimate the coherence of the first principal component and each one of the 404 series, in order to obtain "correlation" at different frequencies. Figure 2 reports the cross-section distribution of the squared coherence values at three frequencies: $0, \pi / 6$ (three years periodicity) and $\pi / 2$ (one year periodicity) respectively.

\footnotetext{
${ }^{9}$ The height of the spectrum at frequency zero is a well-known non parametric measure of the persistence of a time series.

${ }^{10}$ These findings are in line with Clark (2003)'s results. He also shows that the common factor of the disaggregate US inflation rates is more persistent than the idiosyncratic components.
} 

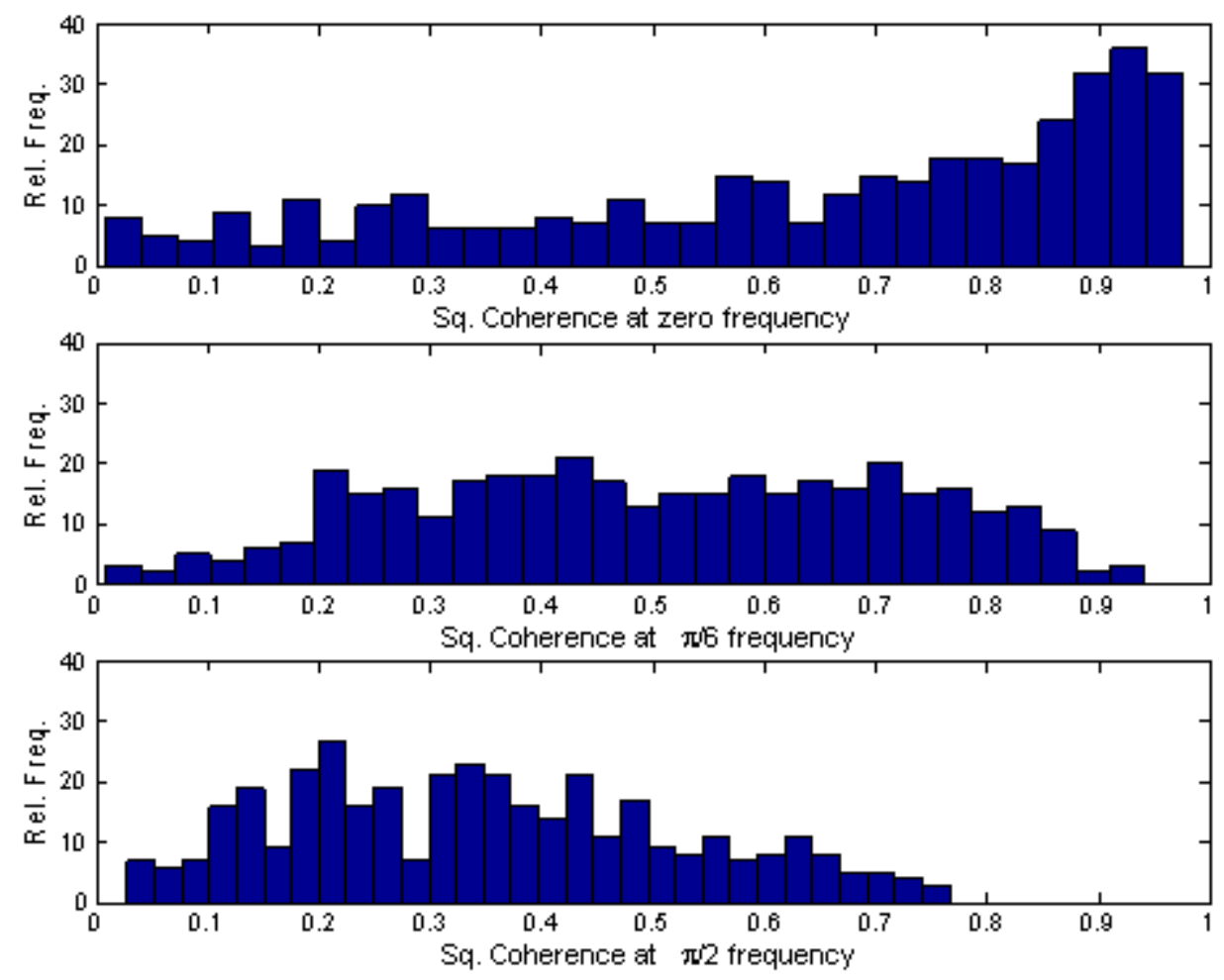

Figure 2: Distribution of the squared coherence.

The differences in the mode and the shape of the histograms across the three frequencies is a first, yet strong, indication of the presumption that the common shock transmission to sectoral inflation is heterogenous. The following section models this heterogeneity.

\section{Model: specification and estimation}

\subsection{The model}

The quarterly rate of change of each sectoral price sub-index is assumed to behave according to (7):

$$
\begin{aligned}
y_{i t} & =\delta_{0 i}+\Psi_{i}(L) u_{t}+\xi_{i t} \\
& =\delta_{0 i}+\frac{\Lambda_{i}(L)}{A_{i}(L)} u_{t}+\frac{\Gamma_{i}(L)}{A_{i}(L)} \epsilon_{i t},
\end{aligned}
$$

with $u_{t} \sim$ i.i.d. $(0,1)$ and $\epsilon_{i t} \sim$ i.i.d. $\left(0, \sigma_{i}^{2}\right), i=1, \ldots, N$. The above polynomials in the lag operator satisfy $\Lambda_{i}(z) \neq 0, \Gamma_{i}(z) \neq 0, A_{i}(z) \neq 0|z| \leq 1$. Each $y_{i t}$ behaves as a stationary 
$\operatorname{ARMA}\left(p_{i}, q_{i}\right)$ with a possibly non zero mean, where $1 \leq p_{i}, q_{i} \leq 2$, in the estimation part, and the order $q_{i}, p_{i}$ of the models are estimated based on the Akaike criteria. Note that we are imposing that the common part, involving the $u_{t}$, and the idiosyncratic part, involving the $\epsilon_{i, t}$, have the same autoregressive structure but they are not constrained in the moving average part. Moreover, for the sake of simplicity, we are also assuming that both the common and the idiosyncratic component have an MA component at most of order $q_{i}$ in both cases. These assumptions simplify greatly the estimation procedure and, at the same time, allow a sufficiently rich dynamics. Note that the sectoral coefficients are estimated freely so that, for example, the parameters in $\Lambda_{i}(L)$ and $\Gamma_{i}(L)$ are sector specific.

\subsection{The estimation strategy}

The estimation of model (8) is non standard. First, the large dimensionality (large $N$ ) rules out the recourse to the conventional Kalman filter approach. Second, the recent techniques for estimation of dynamic factor models, all based on the principal component approach such as Stock and Watson (2002) and Forni et al. (2005), would be inappropriate in our model due to the presence of sector specific autoregressive components, $A_{i}(L)$. This is why we estimate the parameters of the model (8) by means of a multi-stage procedure:

(i) For each unit $i$, we estimate an $\operatorname{ARMA}\left(p_{i}, q_{i}\right)$ with non-zero mean but without distinguishing between the common and the idiosyncratic component. In fact the sum of two moving average components of finite order,

$$
\Lambda_{i}(L) u_{t}+\Gamma_{i}(L) \epsilon_{i t} \equiv B_{i}(L) z_{i t},
$$

turns out to be an $M A$ of the same order with polynomial $B_{i}(L)$ and an innovation sequence $z_{i, t}$ (we are not interested in extracting the $z_{i, t}$ although it is technically possible). Moreover, we do not need to specify the coefficients of $B_{i}(L)$ as a function of the coefficients $\Lambda_{i}(L), \Gamma_{i}(L)$, in order to obtain consistent estimate of the constant term, $\delta_{0 i}$, and of the coefficients of autoregressive part, $A_{i}(L)$;

(ii) we average the estimated MA component $\hat{B}_{i}(L) \hat{z}_{i, t}$ across $i$. This yields an estimate $\widehat{x}_{t}^{(N)}$ of $\left(N^{-1} \sum_{i=1}^{N} \Lambda_{i}(L)\right) u_{t}$, where the approximation improves as $N$ grows since the idiosyncratic component $\left(N^{-1} \sum_{i=1}^{N} \Gamma_{i}(L) \epsilon_{i, t}\right)$ vanishes in mean-square as $N \rightarrow \infty$. Thus we fit a finite order $M A$ to the estimated $\widehat{x}_{t}^{(N)}$ and obtain an estimate of the common innovation $\hat{u}_{t}$;

(iii) using the $\hat{u}_{t}$ as an (artificial) regressor, we fit a $\operatorname{ARMAX}\left(p_{i}, q_{i}, q_{i}\right)$ process (an ARMA process with exogenous regressors) to each $y_{i t}$, in order to obtain also consistent estimate of the coefficients of $\Lambda_{i}(L)$ and $\Gamma_{i}(L)$.

The steps (ii) and (iii) of the procedure can be iterated in order to improve the estimate of the common shock as well as of the autoregressive parameters. Such procedure does not require any distributional assumption. Implicitly it requires that both $N, T$ to diverge to infinity. Estimation of each of the ARMA and MA processes is carried out using the ARMAX procedure of MatLab. 
Details of the algorithm can be found in Altissimo and Zaffaroni (2004). The described iterative procedure is similar to a recent modification of the EM algorithm for the estimation of factor models in the presence idiosyncratic autoregressive components recently proposed by Stock and Watson (2005).

\subsection{Results}

\subsubsection{Results for sectorial inflation rates}

This section briefly describes the estimates of over three thousand parameters ( 8 parameters for each of the 404 time series) of the model. First, the estimated common shock $u_{t}$ turns out to be white, with a non-significant autocorrelation, corroborating the i.i.d. hypothesis. Second, we compare (in Figure 3) the distribution of the absolute value of the first loading of the common shock, which is a measure of the size of the effect of the common shock in the individual time series, with the cross-sectional distribution of the standard deviation of the idiosyncratic components. The idiosyncratic volatility $\sigma_{i}$ is substantially larger than the common shock volatility, in fact six times larger. The median of the distribution of the absolute value of the estimated first loading is 0.06 , whereas we obtain 0.38 for the standard deviation of the idiosyncratic component. This strikingly confirms that most of the variance of sectoral prices is indeed due to sector specific shocks. 

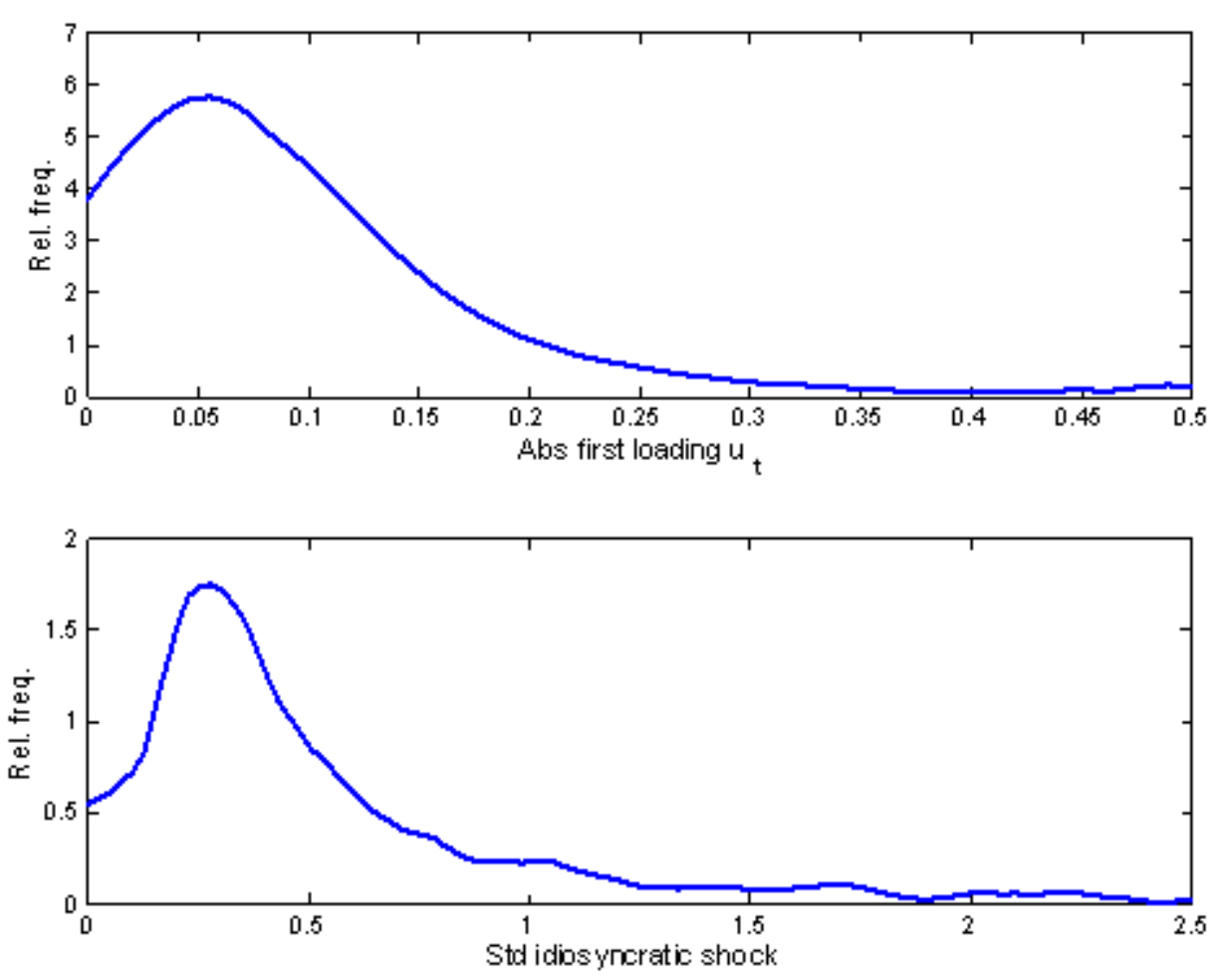

Figure 3: Distributions of $\lambda_{0 i}$ and $\sigma_{i}$.

Third, we turn to $A_{i}(L)$, which dominates the dynamic effects of the common shock on sectoral inflation. In Figure 4 we report the distribution of the signed modulus of the maximal autoregressive root of such polynomia. ${ }^{11}$ This distribution is dense near unity with a median of 0.82 , a mode at 0.93 and a long tail to the left.

\footnotetext{
${ }^{11}$ We did sign such modulus so that we could distinguish between the effect of a negative root from a positive one and also consider the effect of complex roots.
} 


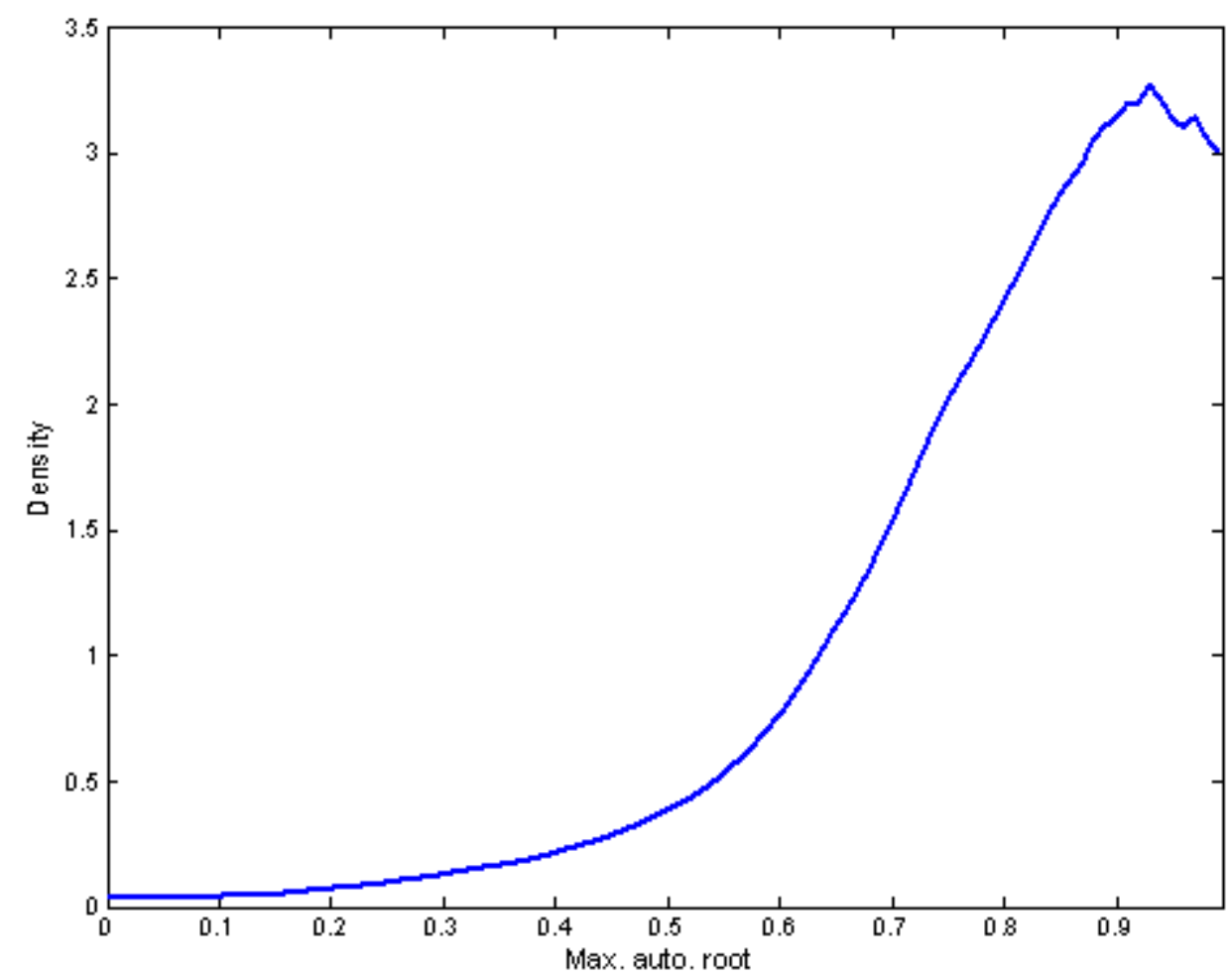

Figure 4: Max autoregressive roots.

Fourth, we compare the dynamics of sectoral inflation rates and main CPI groupings in Table 3. The table reports the number and the relative frequency of series having roots above given thresholds in specific sub-category as well as the total weight of such series in the overall CPI. 
Table 3: Summary statistics of estimated parameters for sectorial inflation rates

\begin{tabular}{|c|c|c|c|c|c|c|c|c|}
\hline \multirow[b]{3}{*}{ EA3 } & \multirow[t]{2}{*}{$\#$} & \multirow[t]{2}{*}{ CPI weight } & \multicolumn{3}{|c|}{ Largest root $>0.875$} & \multicolumn{3}{|c|}{ Largest root $>0.925$} \\
\hline & & & $\#$ & freq & CPI weight & $\#$ & & CPI weight \\
\hline & 404 & 1 & 142 & 0.35 & 0.48 & 54 & 0.27 & 0.26 \\
\hline Germany & 87 & 0.42 & 31 & 0.34 & 0.23 & 11 & 0.12 & 0.14 \\
\hline France & 147 & 0.30 & 55 & 0.38 & 0.15 & 23 & 0.17 & 0.06 \\
\hline Italy & 170 & 0.28 & 56 & 0.35 & 0.11 & 20 & 0.12 & 0.06 \\
\hline Processed food & 65 & 0.14 & 9 & 0.14 & 0.03 & 2 & 0.03 & 0.01 \\
\hline Unprocessed food & 42 & 0.07 & 7 & 0.17 & 0.01 & 3 & 0.07 & 0.00 \\
\hline Non-energy ind. goods & 167 & 0.33 & 68 & 0.42 & 0.14 & 25 & 0.15 & 0.08 \\
\hline Energy goods & 18 & 0.07 & 8 & 0.50 & 0.05 & 5 & 0.31 & 0.03 \\
\hline Services & 114 & 0.39 & 50 & 0.44 & 0.25 & 19 & 0.17 & 0.14 \\
\hline
\end{tabular}

Looking at the cross country pattern, highly persistent sub-sectors in Germany account for a much larger share of the overall euro area CPI; this effect is mainly due the high persistence (autoregressive root of 0.96 ) of German housing expenditure inflation ${ }^{12}$, which accounts for around 10 per cent of the overall CPI. Furthermore, while Energy and Service has the highest frequency of persistent series, Services and, to some degree, Non-energy industrial goods sub-sectors turn out to be more relevant for the dynamics of aggregate inflation because they have a higher weight in the consumption basket.

\subsubsection{Results for aggregate inflation rate}

Given the estimates of the micro parameters, we are now in a position to infer the dynamic properties of the aggregate induced by the behavior of the micro time series. We consider three different types of aggregation schemes. First, we reconstruct the aggregate as an exact weighted average of the individual micro time series and in this way we exactly recover the contribution of the common shocks to the aggregate inflation and to aggregate persistence. Second, we exploit the theoretical link between the distribution of the largest autoregressive root of sectoral inflation rates and the autocovariance structure of the aggregate, as presented in section 2, to infer the dynamic properties of the latter. Third, we consider a so-called naive aggregation scheme based on the (wrong) presumption that the aggregate model has the same functional form as the individual models, in our case an ARMA.

\footnotetext{
${ }^{12}$ The subindex is apartment rent (incl. the value of rent in case of owner-occupied houses), which account for around 20 per cent of the German CPI, while it is only 3 per cent of the Italian and French.
} 


\section{Exact aggregation}

The aggregate inflation data is defined as the weighted average of the sectoral inflation rates. ${ }^{13}$ Therefore using the estimates of the model in (8) it follows:

$$
\begin{aligned}
Y_{n, t} & =\sum_{i=1}^{n} w_{i} y_{i t} \\
& =\sum_{i=1}^{n} w_{i} \widehat{\delta}_{0 i}+u_{t} \sum_{i=1}^{n} w_{i} \frac{\widehat{\Lambda}_{i}(L)}{\widehat{A}_{i}(L)}+\sum_{i=1}^{n} w_{i} \frac{\widehat{\Gamma}_{i}(L)}{\widehat{A}_{i}(L)} \epsilon_{i t} \\
& \equiv \widehat{\delta}_{0}+\widehat{\Psi}(L) u_{t}+\widehat{\xi}_{t}
\end{aligned}
$$

where the $w_{i}$ are the euro area CPI weights. So the aggregate inflation is decomposed into two components, one associated with the common shocks, $u_{t}$, and its propagation mechanism, $\widehat{\Psi}(L)$, and a second associated with the micro idiosyncratic process, $\xi_{t}$. Figure 5 shows the reconstructed aggregate, $Y_{n, t}$, versus its common component, $\widehat{\Psi}(L) \times u_{t}$. There is a high correlation between the two components, around 0.76 , but the former is clearly more volatile pointing to the fact that the idiosyncratic component $\xi_{t}$ is still relevant in the aggregate. Given that the idiosyncratic component has little persistence, $\widehat{\Psi}(L) \times u_{t}$ can be interpreted as a measure of core inflation, possibly relevant for monitoring and forecasting inflation.

\footnotetext{
${ }^{13}$ Statistical offices do not aggregate inflation rates but first they aggregate price indices and then compute the aggregate inflation rate. Here we ignore the possible effect induced by such non-linear transformation. In fact it can be shown that this is not relevant for the dynamic properties of the aggregate.
} 


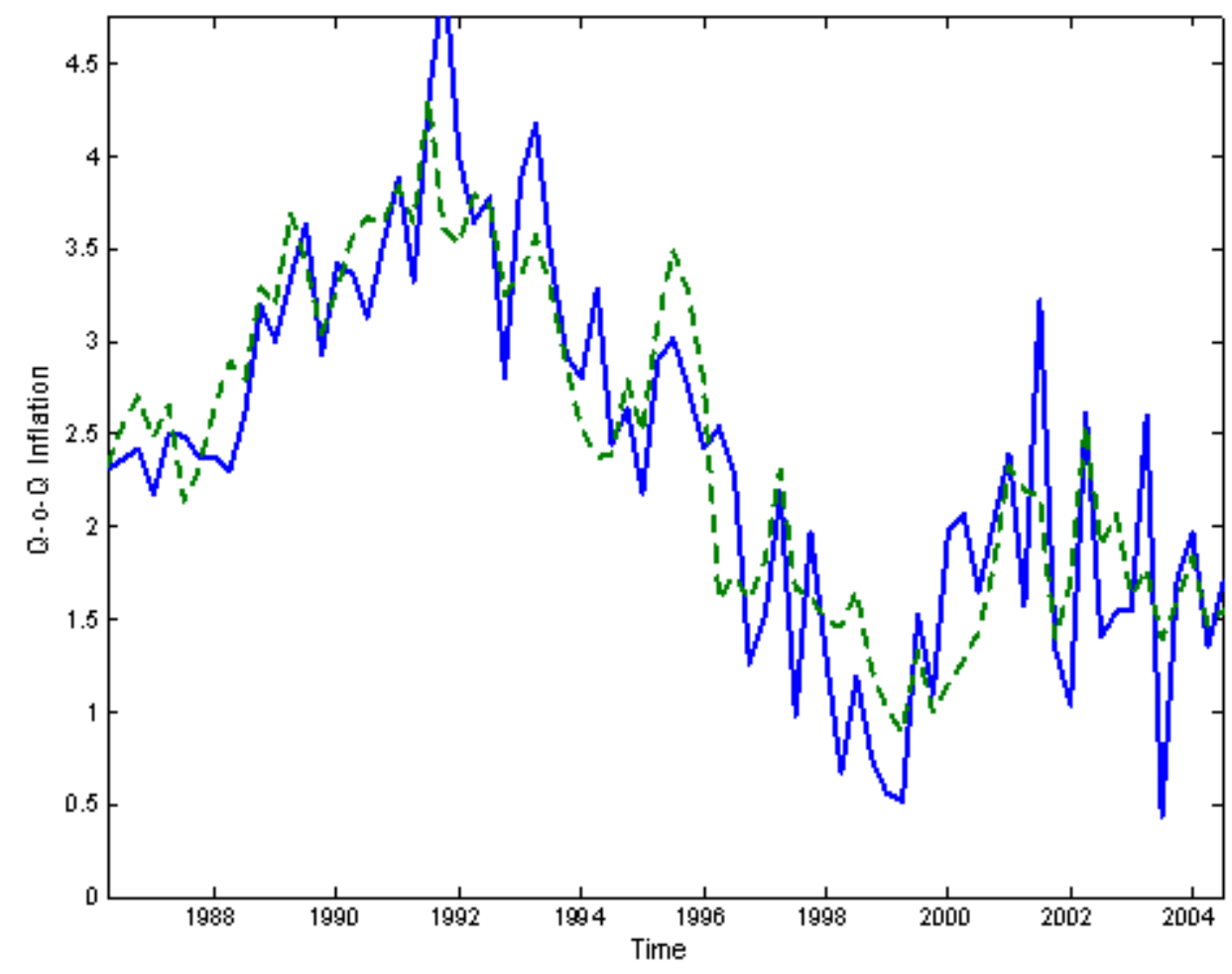

Figure 5: Aggregate inflation (solid line) and common component.

The aggregate propagation mechanism, $\widehat{\Psi}(L)$, is a weighted average of the propagation at micro level, $\widehat{\Psi}_{i}(L)$ and its estimates can be used to recover the autocovariance structure of the component of the aggregate inflation that is driven by the common shock, i.e.: $\widehat{\Psi}(L) \times u_{t}$. The upper panel in Figure 6 shows the autocovariances of aggregate inflation, $Y_{n, t}$, (solid line) versus the one of $\widehat{\Psi}(L) \times u_{t}$ (dotted line), while the lower panel reports the average autocovariance of micro process. ${ }^{14}$ 


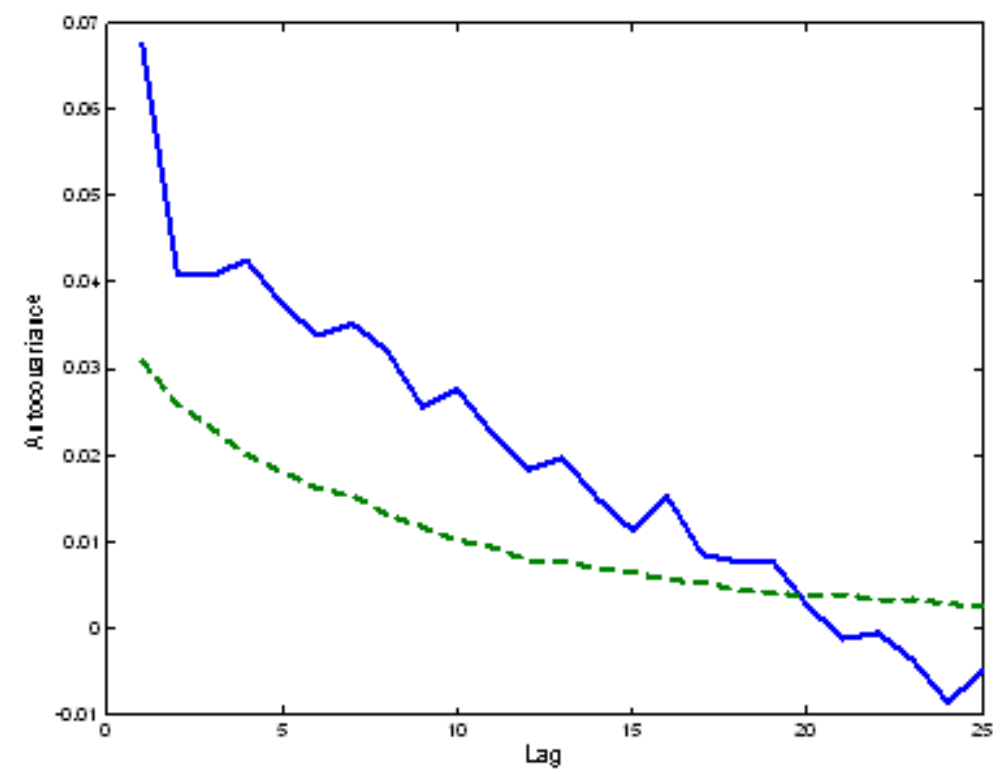

Figure 6a:Autocovariances aggregate (solid) and common component.

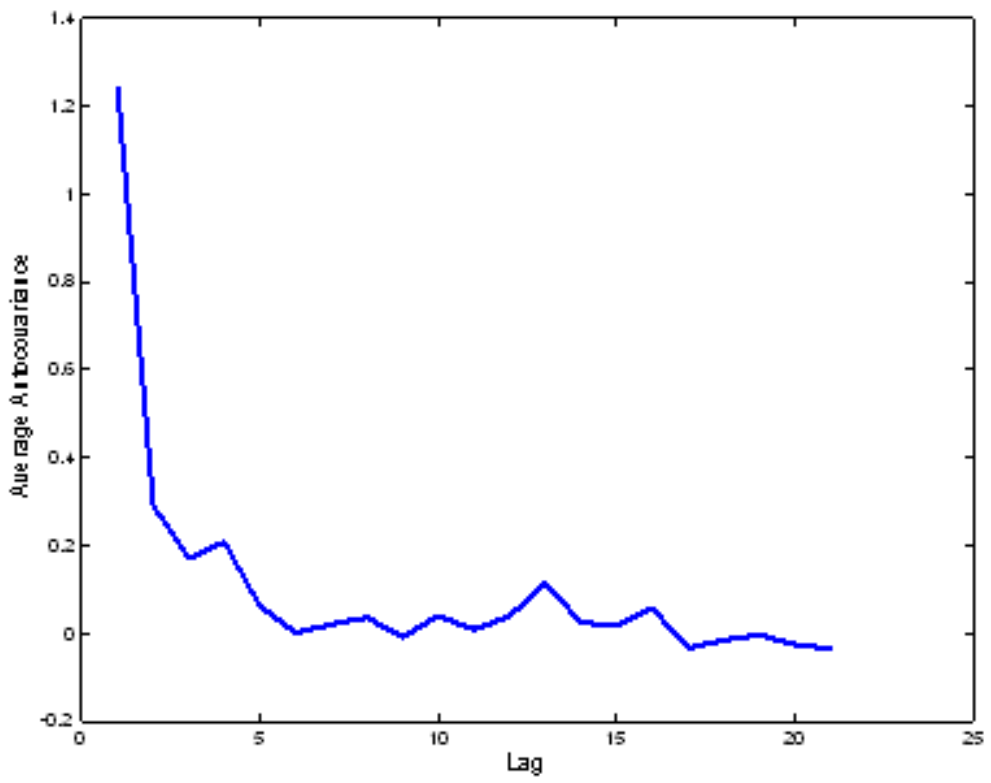

Figure 6b: Average autocovariance.

\footnotetext{
${ }^{14}$ Two graphs were needed given the different scale of the results.
} 
The autocovariance of the reconstructed common components tracks well the covariance structure of the aggregate data, in particular in term of its decay. The variance of the aggregate inflation remains slightly larger than the one of the common component, i.e. the component associated with micro idiosyncratic noise is still relevant in the aggregate data, even if it seems to have little or no dynamic structure. The contrast between the results across the two panels of Figure 6 is even more striking. The cross-sectional average variance of the micro data is an order of magnitude larger than the one of the aggregate data or of the common component in the aggregate data but it decays to zero very quickly. Finally, Figure 7 compares the autocorrelation of the aggregate and the one of the common component. The same conclusion emerges. The common component is the main driver of the dependence of the aggregate data and it properly captures the slow decay of autocorrelation of the data.

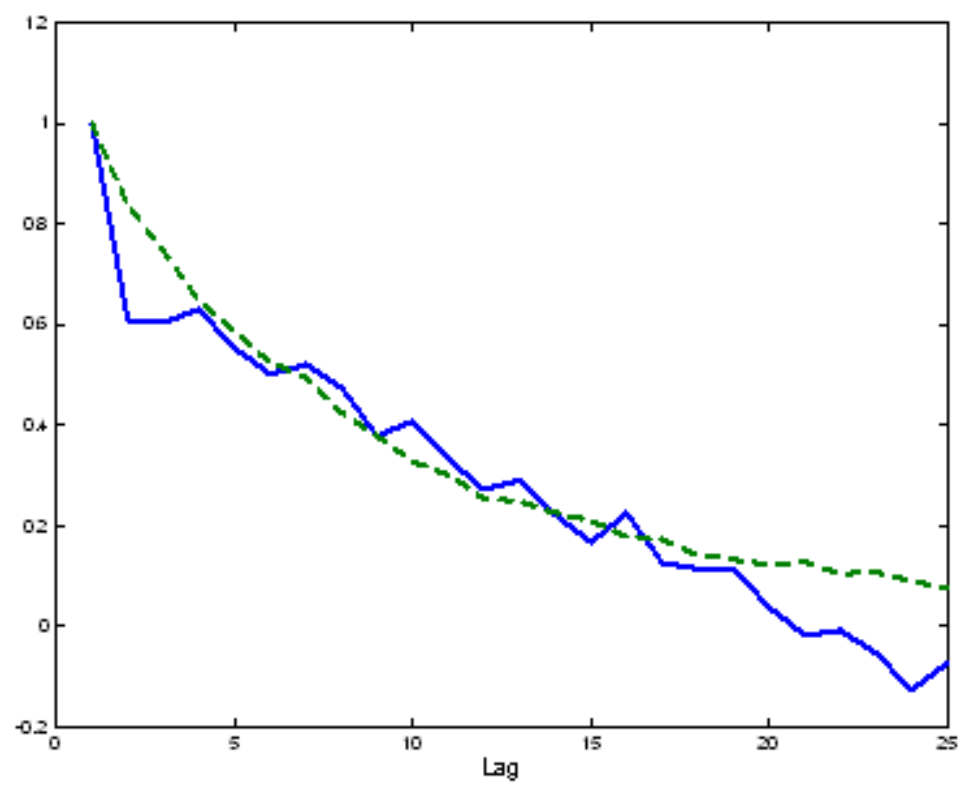

Figure 7: Autocorrelation of aggregate inflation (solid line) and of the common component.

\section{Asymptotic aggregation}

The above discussion has been based on the analysis of the exact autocovariance structure of the common component. Similar conclusion can also be derived by analyzing the cross-sectional distribution of the largest root of the autoregressive part (Figure 4) using the analytic apparatus presented in Section 2.

However we first need to take into account that sectors have different weights in the aggregate. Therefore the distribution in Figure 4 which represents the distribution of the 404 maximal roots 
is not directly relevant because the weighting scheme in the aggregation can change the relative importance of the sectors for the dynamics of the aggregate. To overcome this problem, we implement a relative re-weighting of the 404 maximal autoregressive roots in function of the relative weights of the respective sectors. Precisely, we bootstrap a sample of 10,000 data out of the 404 roots with relative frequency equal to the weighting scheme; hence roots associated to sectors will a larger weight will be re-sampled more often. The density function associated to this simulated sample is compared to the equal weight one in Figure 8.

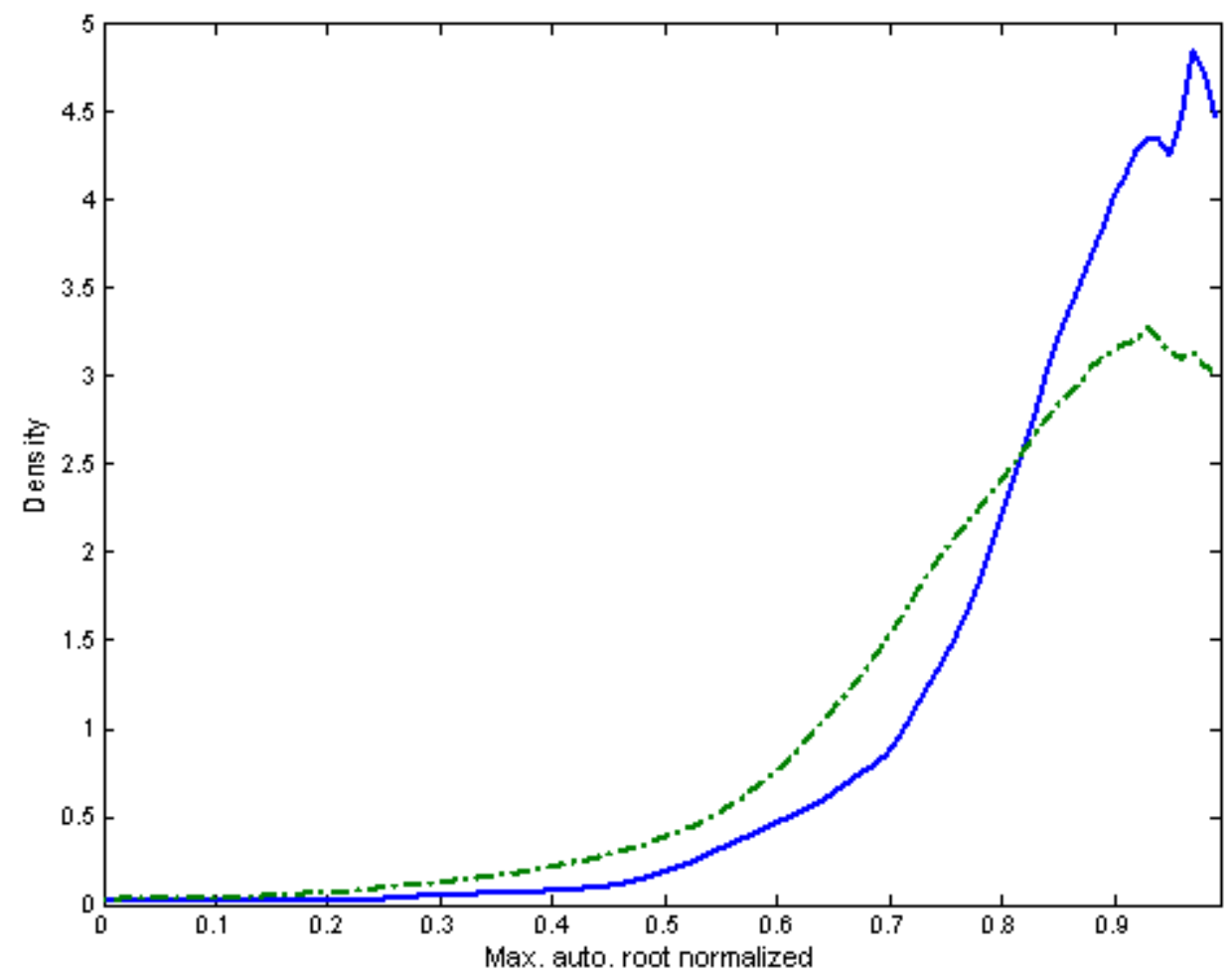

Figure 8: Renormalized distribution of max autoregressive root (solid) and original one.

The implication for aggregation are associated to the behavior near unity of such new distribution. In particular, the above distribution can be approximated near unity as

$$
\hat{f}(\alpha) \sim c(1-\alpha)^{-0.13} \text { as } \alpha \rightarrow 1^{-},
$$

implying that our estimate of the $q$ as in Section 2 is equal to 0.87. Following (5) in Section 2 and the results in Zaffaroni (2004), it is possible to show that the acf of the common component of the aggregate, $\widehat{\Psi}(L) \times u_{t}$, satisfies:

$$
\operatorname{cov}\left(\widehat{\Psi}(L) \times u_{t}, \widehat{\Psi}(L) \times u_{t+k}\right) \sim c k^{-0.74} \text { as } k \rightarrow \infty .
$$


According to definition in Section 2, the process has long memory with parameter $d=0.13$. Therefore, the common component of the aggregate inflation appears to be a stationary but long memory process. Therefore, the acf decays toward zero with an hyperbolic decay, and thus is markedly different from the behavior of the sectoral inflation processes.

We then estimate the memory parameter for the aggregate data using the Whittle parameteric estimator (see Brockwell and Davis, 1991). The direct estimate of the memory parameter on aggregate data turns out to be equal to 0.18 , with standard error of the estimate equals to 0.24 , which, given the distribution reported in the last column of Table 2, is reasonably close to 0.13 , as recovered from the micro structure. Therefore, the aggregate data presents a long memory behavior that is not present in the micro time series; such a long memory behavior appears to be fully accounted for by aggregation.

\section{Naive aggregation}

The above results are framed in term of autocovariance function and they show why the difference in persistence between the micro dynamic and macro one are not necessarily inconsistent. Another way to highlight the effects of aggregation on persistence is to consider the following naive exercise.

We construct an hypothetical ARMA process, whose roots are the mean of the individual roots of the 404 estimated ARMAs. We then contrast the impulse response function to a common shock of such a hypothetical ARMA with the one of the common component, $\widehat{\Psi}(L) \times u_{t}$. The idea of the exercise is to see the aggregate response to shock in case the propagation mechanism is equal across agents versus the case of different propagation mechanisms, i.e., to quantify the effect of heterogeneity and aggregation ${ }^{15}$. Figures 9 compares the impulse response for the ARMA and the one implied by $\Psi(L)$.

\footnotetext{
${ }^{15}$ See also the presentation of similar exercises in the context of micro-founded models, though on hypothetical distribution by Carvalho (2006).
} 


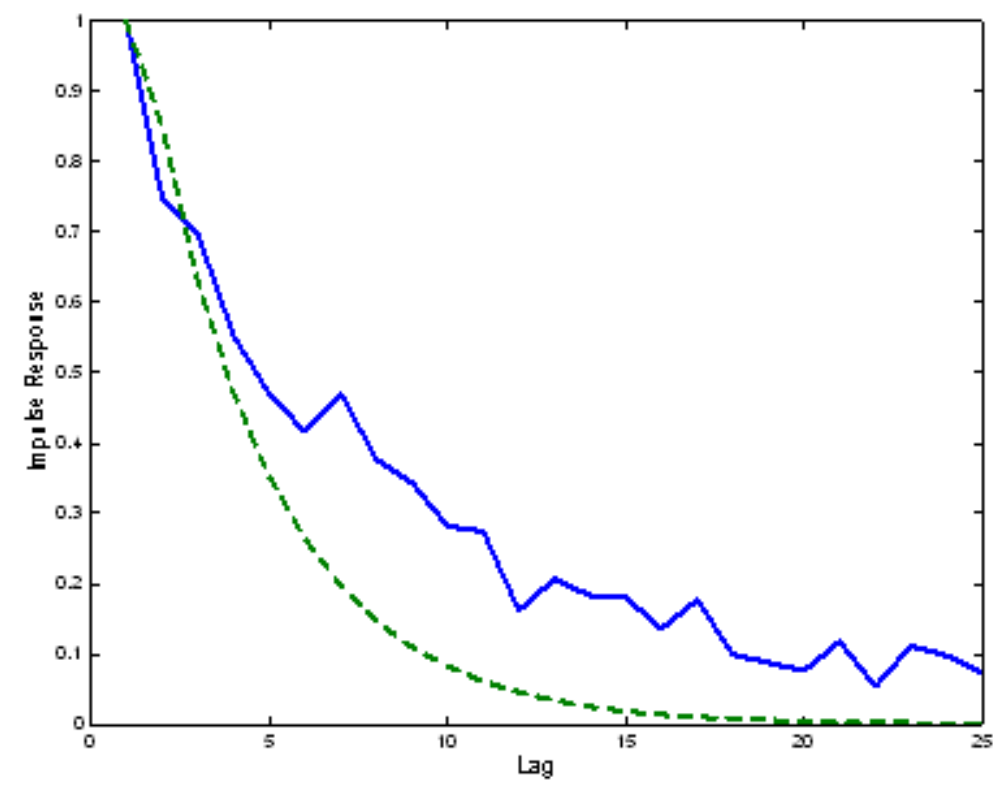

Figure 9: Impulse response of the common component and of the naive ARMA.

The exercise is quite instructive. In the case of a homogeneity of the micro propagation mechanism, after four years (16 periods on the $\mathrm{x}$ axis in Figure 9) a shock $u_{t}$ would be completely absorbed, while in reality, due to the presence of heterogeneity and of some very persistent micro units, around 20 per cent of the original shock has not been absorbed.

Summarizing, we can claim that the analysis of the micro determinants of the aggregate inflation supports the view that aggregate inflation in our sample period can be well described by a stationary but long memory process. We have shown that starting from very simple ARMA process at micro level we have been able to properly reconstruct the dynamic properties of the aggregate. We have also shown that the micro volatility and low persistence can be squared with the aggregate smoothness and persistence.

\section{Conclusion}

In this paper, exploiting the heterogeneity in the inflation dynamics across CPI sub-indices, we investigate the role played by cross-sectional aggregation in explaining some of the difference observed between micro and macro evidence regarding inflation dynamics. We focus in particular on the link between CPI sub-indices and the aggregate CPI. 
We estimated time series models for 404 sub-indices of "items/sectors" of euro area CPI between 1985 and 2003. We fitted ARMA processes at micro level distinguishing the propagation mechanism of the common and idiosyncratic shocks. Our first result is that the propagation mechanism of shocks at the micro level is heterogenous across sectors. This heterogeneity implies a non trivial link between sectoral and aggregate persistence. We perform an aggregation exercise and compute the aggregate persistence as a function of the 404 sectors persistence. Our model is able to square the high volatility and low persistence observed, on average, at the level of sectoral inflation with the smoothness and persistence of the aggregate. The persistence that we obtain through this aggregation exercise mimics remarkably well the persistence observed in the aggregate inflation. In particular, aggregate inflation turns out to be a stationary but long-memory process and the persistence of the aggregate inflation is mainly due to the high persistence of some sub-indices mainly concentrated in the service sector, such as housing rents in Germany.

Altogether, this paper demonstrated the importance of heterogeneity and aggregation for understanding the persistence of inflation at the macroeconomic level. We leave the design and estimation of stylized models of the business cycle that can be consistent with both heterogeneity at the micro level and the implied persistence at the macro level for future research. 


\section{Data appendix}

\section{The French CPI sub-indices}

The French data consist of 161 monthly sub-indices. They are available since 1972 and they have been back-dated the INSEE CPI (1998 base year). The later is publicly available since 1990 for 148 sub-indices while the prices of 13 items enter the CPI basket only after this date.

\section{The German CPI sub-indices}

The German data consist of 100 prices of the 3 Digits classification of HICP sub-indices. These prices are available monthly from early 90s to 2004 .

To back date the HICP, we used about 150 3-digits sub-indices of the 1990 base year CPI data, which are available between 1985 and 1995.

\section{The Italian CPI sub-indices}

The Italian data consist of 167 monthly indices underlying the Italian CPI constructed by ISTAT. The data, kindly provided by the Bank of Italy Research Department, start in 1980 and were rebased to 1995 equal to 100. The full list, and corresponding description, of the sectors is available upon request from the authors.

\section{Seasonal adjustment}

The data were seasonally adjusted with TRAMO-SEATS. The main advantage of this routine is that it is used regularly for the official HICP statistics, and that it allows for integrated seasonal components. This latter aspect is particularly important for our data because EUROSTAT has required that, from the mid-1990's on, the biannual sales campaigns are reflected in the HICP sub-indices of interest. This may affect in particular our French and our German data. As a matter of facts, the Banca d'Italia keeps track of the prices both with the new method and consistently with the historical data. And we used the historically consistent series.

In the seasonal adjustment procedure, we utilized the longest available monthly series, i.e. 1972-2004 for France, 1981-2004Q2 for Italy and 1985-2004 for Germany.

The monthly price level has been transformed into quarterly average and the analysis has been performed on quarter on quarter inflation rates. We use this frequency both to limit the noise of the monthly series and to compare directly our results with the business cycle literature and available studies of sectoral inflation in the euro area (e.g. Lünnemann and Mathä, 2004) and elsewhere Cecchetti and Debelle (2004).

\section{Data cleaning}

We further clean our data according to the following steps. First, we eliminate all the series that start only in the mid 1990's. This is because these series do not have enough degrees of freedom to carry out the estimation of ARMA models. We exclude from our sample 8 French and 9 German sub-indices that are available only after 1995, 1998 or 2000.

Second, we eliminate all the series which are adjusted at rare discrete steps. The typical such series include the price of Tobacco or mailing services. We exclude 6 German, 4 French and 12 Italian sub-indices of this type. 
Altogether we keep 404 sub-indices out of the 444 available in the initial dataset, 377 of which are available from 1985 Q1 to 2004Q2. A last step before, the estimation is to corrections of outliers in the inflation series. We filter out these outliers by replacing observations that are more than 3 standard deviations away from the time series mean of each inflation series by a local median observation. This outlier correction mainly eliminates discrete shifts in the levels of the price indices.

Figure A1 plots the time series of the aggregates that we can reconstruct from the wellbehaved inflation series at the national level and for the aggregate of the three countries (using 1995 PPP-GDP weights of 0.422, 0.296 and 0.282 for Germany, France and Italy, respectively) together with the official CPI inflation rate. We take from the picture that our sub-set of wellbehaved sectoral inflation series offers, when aggregated, a reasonable approximation of the official aggregate index. 
Figures
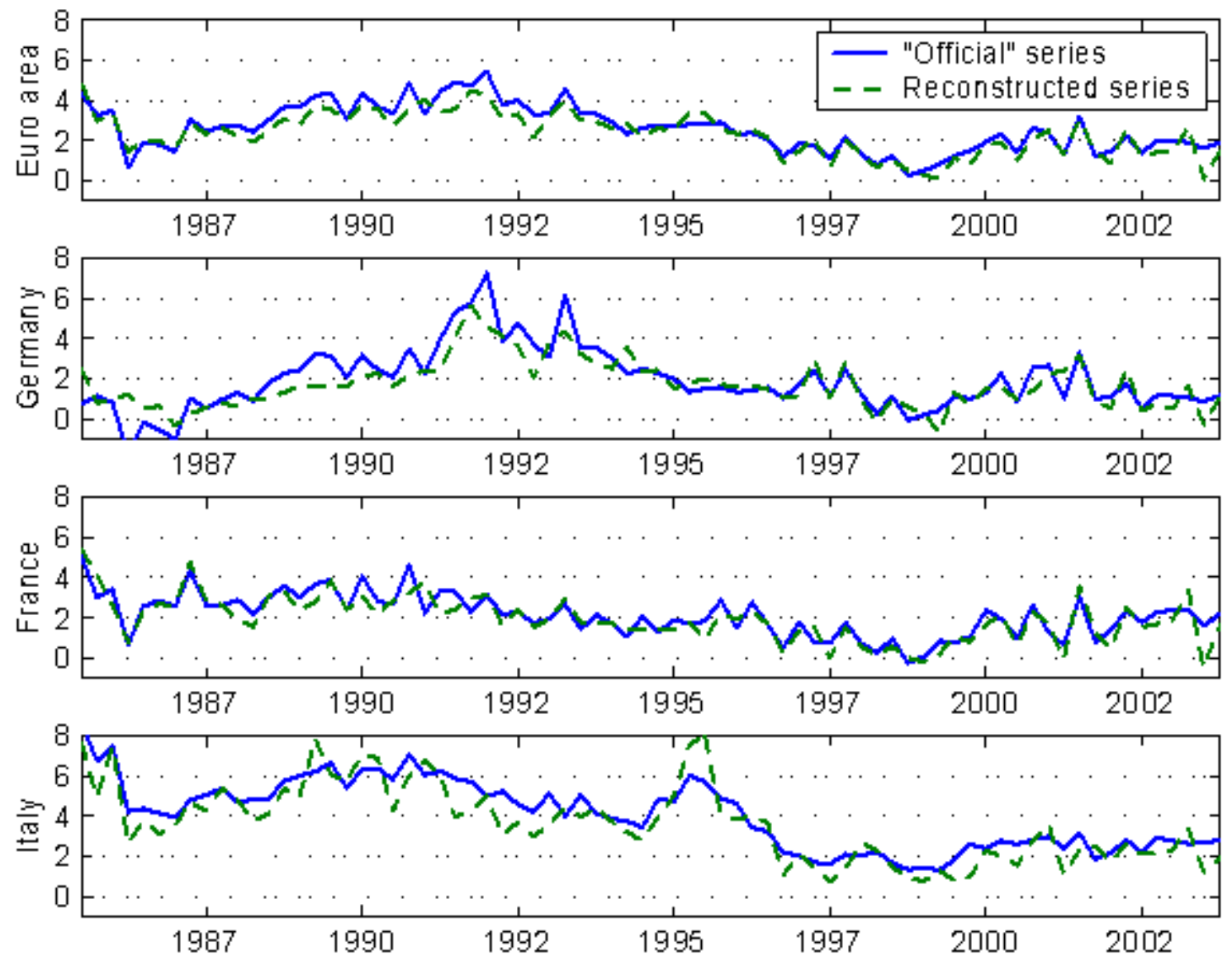

Figure A1: Aggregate q-o-q "official" and reconstructed inflation rates 


\section{References}

[1] Altissimo F. and P. Zaffaroni (2004), "Towards understanding the relationship between aggregate fluctuations and individual heterogeneity", Preprint.

[2] Attali J. (1993), "Verbatim I, 1981-1986", Fayard.

[3] Bilke L. (2005), "Break in the mean and persistence of inflation: a sectoral analysis of French CPI", ECB working paper 413.

[4] Bils, M., and P. Klenow (2004), "Some evidence on the importance of sticky prices", Journal of Political Economy, 112 (5), pp 947-85.

[5] Boivin, J. M. Giannoni and I. Mihov (2006), "Sticky prices and monetary policy: Evidence from disaggregated U.S. data", Columbia mimeo presented at the 2006 NBER Summer Institute.

[6] Brockwell J., and R. Davis (1991), Time Series: Theory and Methods, Springer Verlang,

[7] Caballero, R., and E. Engel (2004), "Adjustment is much slower than you think ", mimeo.

[8] Carvalho,. C. (2005), "Heterogeneity in price setting and the real effects of monetary shocks", Princeton University mimeo.

[9] Cecchetti S. and G. Debelle (2004), "Has the inflation process changed?", Economic Policy 21(46), pages 311-352.

[10] Chari, V., P. Kehoe and E. McGrattan (2000), "Sticky price models of the business cycle: can the contract multiplier solve the persistence problem?", Econometrica 68 (5), pp 1151-79.

[11] Christiano L.J., M. Eichenbaum and C. L. Evans (2005), "Nominal rigidities and the dynamic effects of a shock to monetary policy", Journal of Political Economy 113 (1), 1-45.

[12] Clarida R., J. Galì and M. Gertler (2000), "Monetary policy rules and macroeconomic stability: evidence and some theory", Quarterly Journal of Economics 115 (1), 147-180.

[13] Clark T. (2003), "Disaggregate evidence on the persistence of US consummer price inflation", Journal of Applied Econometrics.

[14] Corvoisier S. and B. Mojon (2005), "Breaks in the mean of inflation: How they happen and what to do with them", ECB Working Paper No. 451.

[15] Dhyne E. L. Alvarez, H. Le Bihan, G. Veronese, D. Dias, J. Hoffman, N. Jonker, P. Lünnemann, F. rumler and J. Vilmunen (2005), "Price setting in the euro area: Some stylised facts from invidual consumer price data", ECB Working paper 523. 
[16] Forni, M., M. Hallin, M. Lippi, and L. Reichlin (2000): "The generalized factor model: identication and estimation," The Review of Economics and Statistics, 82, 540-554.

[17] Forni, M., M. Hallin, M. Lippi, and L. Reichlin (2005): "The generalized factor model: one sided estimation and forecasting," Journal of the American Statistical Association 100, $830-40$.

[18] Forni, M., and M. Lippi (1997), Aggregation and the microfoundations of dinamic macroeconomics, Oxford University Press.

[19] Galì J. and M. Gertler (1999), "Inflation dynamics: A structural econometric analysis", Journal of monetary Economics 44, 195-222.

[20] Golosov M. and R. E. Lucas Jr. (2006), "Menu costs and Phillips curves", MIT mimeo.

[21] Granger, C. (1980): "Long memory relationships and the aggregation of dynamic models," Journal of Econometrics, 14, 227-238.

[22] Gressani D., Guiso L. and I. Visco (1988), "Disinflation in Italy: An Analysis with the Econometric Model of the Bank of Italy", Journal of Policy Modelling, 10(2): 163-203.

[23] Horváth R. and F. Coricelli (2006), "Price Setting Behavior: Micro Evidence from Slovakia", revised version of CEPR Discussion paper 5445.

[24] Imbs, J., H. Mumtaz, M. Ravn and H. Rey (2005), "PPP strikes back: aggregation and the real exchange rate", Quarterly Journal of Economics CXX (1), 1-43.

[25] Levin, A., J. Piger (2004), "Is inflation persistence intrinsic in industrial economies?", ECB Working Paper No. 334.

[26] Lünnemann P. and T. Mathä (2004), "How persistent is disaggregate inflation? An analysis accross EU15 countries and HICP sub-indices", ECB working paper 415.

[27] Mankiw, G. (2001), "The inexorable and mysterious trade off between inflation and unemployment", NBER WP 7884.

[28] Mackowiak, B. and M. Wiederholt (2005), "Optimal sticky prices under rational inattention", Humboldt University mimeo.

[29] O' Reilly G. and K. Whelan (2005), "Has euro area inflation persistence changed over time?", Review of Economics and Statistics, 87(4): 709-20.

[30] Robinson, P. M. (1978): "Statistical inference for a random coefficient autoregressive model", Scandinavian Journal of Statistics 5, 163-168. 
[31] Sbordone A. (2003), "Prices and unit labor costs: A new test of price stickiness", Journal of Monetary Economics 51(4), 837-859.

[32] Smets F. and R. Wouters (2003), "An estimated dynamic stochastic general equilibrium model of the euro area, Journal of the European Economic Association. September 2003; 1(5): 1123-75.

[33] Stock, J., and M. Watson (2002): "Macroecnomic forecasting using diffusion indices", Journal of Business and Economics Statistics 20, 147-62.

[34] Stock, J., and M. Watson (2005): "An empirical comparison of methods for forecasting using many predictors", Harvard mimeo.

[35] Zaffaroni, P. (2004), "Contemporaneous aggregation of linear dynamic models in large economies", Journal of Econometrics 120, 75-102. 


\section{European Central BankWorking Paper Series}

For a complete list of Working Papers published by the ECB, please visit the ECB's website (http://www.ecb.int)

69I "The yield curve as a predictor and emerging economies" by A. Mehl, November 2006.

692 "Bayesian inference in cointegrated VAR models: with applications to the demand for euro area M3” by A.Warne, November 2006.

693 "Evaluating China's integration in world trade with a gravity model based benchmark" by M. Bussière and B. Schnatz, November 2006.

694 "Optimal currency shares in international reserves: the impact of the euro and the prospects for the dollar" by E. Papaioannou, R. Portes and G. Siourounis, November 2006.

695 “Geography or skills:What explains Fed watchers' forecast accuracy of US monetary policy?" by H. Berger, M. Ehrmann and M. Fratzscher, November 2006.

696 "What is global excess liquidity, and does it matter?" by R. Rüffer and L. Stracca, November 2006.

697 "How wages change: micro evidence from the International Wage Flexibility Project" by W.T. Dickens, L. Götte, E. L. Groshen, S. Holden, J. Messina, M. E. Schweitzer, J. Turunen, and M. E.Ward, November 2006.

698 “Optimal monetary policy rules with labor market frictions” by E. Faia, November 2006.

699 "The behaviour of producer prices: some evidence from the French PPI micro data" by E. Gautier, December 2006.

700 "Forecasting using a large number of predictors: Is Bayesian regression a valid alternative to principal components?” by C. De Mol, D. Giannone and L. Reichlin, December 2006.

$70 \mathrm{I}$ "Is there a single frontier in a single European banking market?" by J.W. B. Bos and H. Schmiedel, December 2006.

702 “Comparing financial systems: a structural analysis” by S. Champonnois, December 2006.

703 "Comovements in volatility in the euro money market" by N. Cassola and C. Morana, December 2006.

704 "Are money and consumption additively separable in the euro area? A non-parametric approach" by B. E. Jones and L. Stracca, December 2006.

705 "What does a technology shock do? A VAR analysis with model-based sign restrictions" by L. Dedola and S. Neri, December 2006.

706 'What drives investors' behaviour in different FX market segments? A VAR-based return decomposition analysis” by O. Castrén, C. Osbat and M. Sydow, December 2006.

707 "Ramsey monetary policy with labour market frictions” by E. Faia, January 2007. 
708 "Regional housing market spillovers in the US: lessons from regional divergences in a common monetary policy setting” by I.Vansteenkiste, January 2007.

709 "Quantifying and sustaining welfare gains from monetary commitment” by P. Levine, P. McAdam and J. Pearlman, January 2007.

710 "Pricing of settlement link services and mergers of central securities depositories" by J.Tapking, January 2007.

7II “What "hides” behind sovereign debt ratings?” by A. Afonso, P. Gomes and P. Rother, January 2007.

712 “Opening the black box: structural factor models with large cross-sections” by M. Forni, D. Giannone, M. Lippi and L. Reichlin, January 2007.

713 "Balance of payment crises in emerging markets: How early were the "early" warning signals?" by $M$. Bussière, January 2007.

714 "The dynamics of bank spreads and financial structure" by R. Gropp, C. Kok Sørensen and J.-D. Lichtenberger, January 2007.

715 “Emerging Asia's growth and integration: How autonomous are business cycles?” by R. Rüffer, M. Sánchez and J.-G. Shen, January 2007.

716 "Adjusting to the euro" by G. Fagan and V. Gaspar, January 2007.

717 "Discretion rather than rules? When is discretionary policy-making better than the timeless perspective?" by S. Sauer, January 2007.

718 “Drift and breaks in labor productivity” by L. Benati, January 2007.

719 “US imbalances: the role of technology and policy” by R. Bems, L. Dedola and F. Smets, January 2007.

720 "Real price wage rigidities in a model with matching frictions" by K. Kuester, February 2007.

721 “Are survey-based inflation expectations in the euro area informative?” by R. Mestre, February 2007.

722 "Shocks and frictions in US business cycles: a Bayesian DSGE approach" by F. Smets and R. Wouters, February 2007.

723 “Asset allocation by penalized least squares” by S. Manganelli, February 2007.

724 "The transmission of emerging market shocks to global equity markets" by L. Cuadro Sáez, M. Fratzscher and C.Thimann, February 2007.

725 "Inflation forecasts, monetary policy and unemployment dynamics: evidence from the US and the euro area" by C. Altavilla and M. Ciccarelli, February 2007.

726 "Using intraday data to gauge financial market responses to Fed and ECB monetary policy decisions" by M.Andersson, February 2007.

727 "Price setting in the euro area: some stylised facts from individual producer price data", by P.Vermeulen, D. Dias, M. Dossche, E. Gautier, I. Hernando, R. Sabbatini and H. Stahl, February 2007. 
728 "Price changes in finland: some evidence from micro cpi data", by S. Kurri, February 2007.

729 "Fast micro and slow macro: can aggregation explain the persistence of inflation?", by F. Altissimo, B. Mojon and P. Zaffaroni, February 2007. 


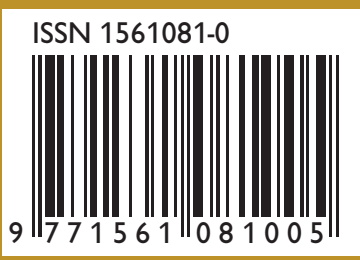

